\title{
IMPROVING READING SKILLS AT FIRST CLASS STUDENTS SDN 04 KOTO RANAH KECAMATAN IV NAGARI BAYANG UTARA KABUPATEN PESISIR SELATAN THROUGH MODEL OF SINGING LEARNING
}

\author{
JAMINAR \\ Volume 1 Nomor 2 \\ JIPS \\ ISSN: 2579-5449 \\ E-ISSN: 2597-6540
}

\begin{abstract}
The existence of elementary school as a basic educational institution is very high to participate in helping children grow. For Students class I SDN 04 Koto Ranah District IV Nagari Bayang Utara Pesisir Selatan District Lesson Year 2015/2016 is a place to play, socialize and also learn is quite representative. In general, people know that learning in class I Sdn 04 Koto Ranah District IV Nagari Bayang Utara Pesisir Selatan District Lesson Year 2015/2016 apply the principle of playing while learning or learning while playing. But in its application, it turns out that between theory and practice are not aligned. It was found that in the first grade students of SDN 04 Koto Ranah, Sub District IV Nagari Bayang Utara, Pesisir Selatan District, the Lesson Year 2015/2016 has been taught the lesson and its delivery as it is to teach the lessons to the children of Advanced School.

Concerns arise when society generally thinks that the standard of teaching success in class I SDN 04 Koto Ranah Subdistrict IV Nagari Bayang Utara Pesisir Selatan District Lesson Year 2015/2016 is students who have completed education in elementary school able to write, read and count. Parents will feel proud when their son graduated from elementary school has been fluent in reading, writing and counting.

be drawn some conclusions that: Reading practice in teaching and learning process with singing techniques more easily ditangkapa by grade I SDN 04 Koto Ranah District IV Nagari Bayang Utara Pesisir Selatan District Lesson 2015/2016. During this activity, there is a seriousness of the children to follow the lesson. Children can learn to read without feeling depressed and always in a pleasant atmosphere. The results of monitoring quantitatively shows that $75 \%$ of children are able to read smoothly so that invites students class I SDN 04 Koto Ranah District IV Nagari Bayang North Pesisir Selatan District Lessons 2015/2016 reading practice with singing techniques proved to foster interest in reading children early on. A teacher meeting program with parents who are held once a month before delivering materials to children is very influential in helping children to succeed in SDN 04 Koto Ranah Sub District IV Nagari Bayang Utara Pesisir Selatan District Lesson 2015/2016. The author realizes that the delivery of the material has not been implemented optimally, given the number of children who exceed the capacity. If implemented more intensively and with the ideal ratio of teachers and children, then the quantitative and qualitative of course the result will be better.
\end{abstract}

Based on what the authors have done, can 


\title{
MENINGKATKAN KEMAMPUAN BACA PADA SISWA KELAS I SDN O4 KOTO RANAH KECAMATAN IV NAGARI BAYANG UTARA KABUPATEN PESISIR SELATAN MELALUI MODEL PEMBELAJARAN MENYANYI
}

\begin{abstract}
ABSTRAK
Keberadaan SD sebagai lembaga pendidikan dasar sekolah sangat tinggi untuk turut berperan serta dalam membantu tumbuh kembang anak. Bagi Siswa kelas I SDN 04 Koto Ranah Kecamatan IV Nagari Bayang Utara Kabupaten Pesisir Selatan Tahun Pelajaran 2015/2016 merupakan tempat bermain, bersosialisasi dan juga belajar adalah cukup representatif. Secara umum masyarakat mengetahui bahwa pembelajaran di kelas I Sdn 04 Koto Ranah Kecamatan IV Nagari Bayang Utara Kabupaten Pesisir Selatan Tahun Pelajaran 2015/2016 menerapkan prinsip bermain sambil belajar atau belajar seraya bermain. Tetapi dalam penerapannya, ternyata antara teori dan praktek tidak sejalan. Banyak ditemukan bahwa pada siswa kelas I SDN 04 Koto Ranah Kecamatan IV Nagari Bayang Utara Kabupaten Pesisir Selatan Tahun Pelajaran 2015/2016 telah diajarkan pelajaran dan penyampaiannya sebagaimana layaknya mengajarkan pelajaran kepada anak-anak Sekolah Tingkat Lanjutan.

Keprihatinan muncul manakala masyarakat secara umum berpendapat bahwa standard keberhasilan pembelajaran di kelas I SDN 04 Koto Ranah Kecamatan IV Nagari Bayang Utara Kabupaten Pesisir Selatan Tahun Pelajaran 2015/2016 adalah anak didik yang telah menamatkan pendidikan di SD mampu menulis, membaca dan berhitung. Orang tua akan merasa bangga apabila anaknya yang tamat dari SD telah lancar membaca, menulis dan berhitung.

Berdasarkan apa yang telah penulis laksanakan, dapat ditarik beberapa kesimpulan yaitu bahwa : Latihan membaca dalam proses belajar mengajar dengan teknik menyanyi lebih mudah ditangkapa oleh siswa kelas I SDN 04 Koto Ranah Kecamatan IV Nagari Bayang Utara Kabupaten Pesisir Selatan Tahun Pelajaran 2015/2016 . Selama kegiatan ini berlangsung, terlihat adanya kesungguhan dari anak-anak untuk mengikuti pelajaran. Anak-anak bisa belajar membaca tanpa merasa tertekan dan selalu dalam suasana yang menyenangkan. Hasil monitoring secara kuantitatif menunjukkan bahwa $75 \%$ anak-anak mampu membaca lancar sehingga mengajak siswa kelas I SDN 04 Koto Ranah Kecamatan IV Nagari Bayang Utara Kabupaten Pesisir Selatan Tahun Pelajaran 2015/2016 latihan membaca dengan teknik menyanyi terbukti mampu menumbuhkan minat baca anak sejak dini. Program pertemuan guru dengan orang tua murid yang dilaksanakan sebulan sekali sebelum menyampaikan materi kepada anak-anak sangat besar pengaruhnya dalam membantu keberhasilan anak-anak belajar di SDN 04 Koto Ranah Kecamatan IV Nagari Bayang Utara Kabupaten Pesisir Selatan Tahun Pelajaran 2015/2016 . Penulis menyadari bahwa penyampaian materi tersebut belum dilaksanakan secara maksimal, mengingat jumlah anak yang melebihi kapasitas. Apabila dilaksanakan lebih intensif dan dengan rasio perbandingan guru dan anak yang ideal, maka secara kuantitatif maupun kualitatif tentu hasilnya akan lebih baik
\end{abstract}

Kata Kunci: meningkatkan kemampuan baca, model pembelajaran menyanyi 


\section{PENDAHULUAN}

Latar Belakang Penelitian Tindakan, Keberadaan SD sebagai lembaga pendidikan dasar sekolah sangat tinggi untuk turut berperan serta dalam membantu tumbuh kembang anak. Bagi Siswa kelas I SDN 04 Koto Ranah Kecamatan IV Nagari Bayang Utara Kabupaten Pesisir Selatan Tahun Pelajaran 2015/2016 merupakan tempat bermain, bersosialisasi dan juga belajar adalah cukup representatif. Secara umum masyarakat mengetahui bahwa pembelajaran di kelas I Sdn 04 Koto Ranah Kecamatan IV Nagari Bayang Utara Kabupaten Pesisir Selatan Tahun Pelajaran 2015/2016 menerapkan prinsip bermain sambil belajar atau belajar seraya bermain. Tetapi dalam penerapannya, ternyata antara teori dan praktek tidak sejalan. Banyak ditemukan bahwa pada siswa kelas I SDN 04 Koto Ranah Kecamatan IV Nagari Bayang Utara Kabupaten Pesisir Selatan Tahun Pelajaran 2015/2016 telah diajarkan pelajaran dan penyampaiannya sebagaimana layaknya mengajarkan pelajaran kepada anak-anak Sekolah Tingkat Lanjutan.

Keprihatinan muncul manakala masyarakat secara umum berpendapat bahwa standard keberhasilan pembelajaran di kelas I SDN 04 Koto Ranah Kecamatan IV Nagari Bayang Utara Kabupaten Pesisir Selatan Tahun Pelajaran 2015/2016 adalah anak didik yang telah menamatkan pendidikan di SD mampu menulis, membaca dan berhitung. Orang tua akan merasa bangga apabila anaknya yang tamat dari SD telah lancar membaca, menulis dan berhitung.

Lebih memprihatinkan lagi, saat ini ada sementara Sekolah Dasar yang hanya menerima peserta didik baru melalui tes kemampuan membaca, menulis dan berhitung. Hal itu tentu membuat resah orang tua murid dan memicunya untuk menempuh berbagai cara agar anaknya ketika tamat SD sudah dapat membaca, menulis dan berhitung., tanpa mempertimbangkan bahwa ambisi orang tua tersebut akan membuat anak depresi dan stress.

Menghadapi permasalahan demikian, guru tentu akan bimbang. Apabila guru tidak mampu memenuhi tuntutan masyarakat, bisa jadi sekoalah tempat guru tersebut mengajar tidak akan diminati masyarakat. Tetepi apabila memenuhi tuntutan masyarakat, tentunya sekolah akan beralih fungsi. SD bukan lagi sebagai taman yang begitu indah, bukan lagi sebagai tempat bermain dan belajar, tetapi SD merupakan tempat untuk mengkarbit anak sebagai calon penerus bangsa.

SD merupakan lembaga pendidikan formal dasar yang paling indah sekaligus sebagai lembaga untuk membentuk jiwa dan karsa. Salah satu upaya untuk mengoptimalkan keseimbangan otak kanan dan otak kiriini, adalah dengan cara mempersiapkan anak belajar membaca melalui kegiatan menyanyi.

Rumusan Masalah, Penulis menggunakan teknik menyanyi dalam upaya menumbuhkan kesiapan membaca pada siswa kelas I SDN 04 Koto Ranah Kecamatan IV Nagari Bayang Utara Kabupaten Pesisir Selatan Tahun Pelajaran 2015/2016 . Pertimbangan penulis menggunakan teknik menyanyi sebagai dasar pengajaran di kelas I SDN 04 Koto Ranah Kecamatan IV Nagari Bayang Utara Kabupaten Pesisir Selatan Tahun Pelajaran 2015/2016 agar harapan bahwa anak mampu membaca, hendaknya dapat disikapi dengan cara bijaksana. Tanpa harus mengecewakan harapan orang tua, tetapi juga, dalam menumbuhkan kesiapan membaca, hendaknya jangan sampai membebani anak dan jangan sampai mengesampingkan prinsip pembelajaran di SD yaitu belajar sambil bermain.

Disatu sisi, guru sangat perlu meninjau kembali kebijakannya dalam memenuhi tuntutan masyarakat. Teknik pembelajaran skolastik khususnya kesiapan membaca anak SD hendaknya sesuai porsi anak. Disisi lain, Menyanyi sudah sejak lama digunakan dalam kegiatan belajar mengajar di kelas I SDN 04 KOTO RANAH Kecamatan IV Nagari Bayang Utara Kabupaten Pesisir Selatan Tahun Pelajaran 2015/2016 . Kreatifitas guru dalam mengolah lagu kanak-kanak sehingga dapat digunakan sebagai media pembelajaran membaca anak-anak perlu disosialisasikan. 


\section{METODE PENELITIAN}

Guru sebagai peneliti sekaligus yang melakukan tindakan didalam kelas. Tindakan yang dilakukan untuk mengatasi permasalahan yang dirumuskan dirancang dalam bentuk siklus banyaknya siklus yang direncanakan adalah dua siklus. Satu siklus terdiri dari dua pertemuan, masing-masing dua jam pelajaran. Tujuan pembelajaran pada pertemuan pertama adalah membaca. Tujuan pembelajaran yang akan dicapai pada pertemuan kedua adalah menulis pengalaman pribadi.

Siswa kelas I SDN 04 Koto Ranah Kecamatan IV Nagari Bayang Utara Kabupaten Pesisir Selatan Tahun Pelajaran 2015/2016 .

\section{Subyek Penelitian dan Kolaborasi}

Subyek : Siswa kelas I

Kolaborasi : Guru Bidang studi Bahasa Indonesia

Jenis data dalam penelitian ini adalah data verbal dan data non verbal. Data verbal berupa hasil tes tulis siswa, yakni menganalisis bacaan dengan menggunakan gaya belajar menyanyi. Selanjutnya data verbal nonverbal adalah antusiasme siswa saat mengikuti proses pembelajaran dan pengeksoresian siswa terhadap nyanyian tersebut.

Data verbal dan nonverbal diperoleh dengan menggunaakan tes dan non tes. Tes dilakukan di awal kegiatn pembelajaran (protes) dan di akhir kegiatan pembelajaran (Protes). Tes yang diberikan kepada siswa adalah tes tulis.

Selanjutnya teknik nontes dilakukan pada saat kegiatan pembelajaran berlangsung. Fungsi non-tes ini adalah untuk mengukur kemampuan siswa menulis dan mengekspresikan puisi tersebut. Selain itu teknik nontes ini juga digunakan untuk mengetahui antusiasme siswa dalam mengikuti kegiatan pembelajaran.

Instrumen Penelitian Penelitian tindakan kelas ini menggunakan dua macam instrumen penjaring data. Instrumen penjaring data tersebut adalah : (1) tes,dan (2) Non-tes. Instrumen tes berupa penilaian hasil belajar siswa terhadap nyanyian yang harus diapresiasikannya instrumen non tes berupa : (a) Pedoman Obervesi. (b) Pedoman wwancara untuk guru (c) Pedoman wawancara untuk siswa, serta (d) Koesioner untuk siswa. Instrumen nontes tersebut dapat dilengkapi dengan permasalahan yang timbul pada saat KMB berlangsung, keoptimalan komunikasi di interksi
KMB, Pendapat dan komentar guru dan / atau siswa terhadap KMB.

Penjaringan data dalam penelitian ini menggunakan instrumen sebagai berikut : Dalam penelitian ini akan digunakan tiga instrumen, yaitu : berupa hasil belajar. Tes, yang berupa tes uraian akan digunakan untuk mengukur kemampuan menulis dan mengapresiasikan siswa dalam menulis dan membaca, dimana dalam hal ini digunakan sebagai tes awal dan tes akhir. Hasil tes awal menggambarkan kemampuan intuisi awal siswa sebelum diberi model pembelajaran yaitu apresiasi bacaan melalui menyanyi, sedangkan hasil tes akhir menggambarkan hasil belajar siswa sekaligus peningkatan kemampuan penalaran siswa setelah diberi model pembelajaran ini. Adapun jenis tes yang digunakan adalah tes bentuk mengarang. Tes dibuat berdasarkan materi yang diajarkan yaitu berupa lokalisasi bacaan.

Kriteria penilaian untuk setiap butir tes berdasarkan rambu-rambu (marking scheme) yang telah dibuat sebelumnya yaitu dengan memberikan skor $0-8$ dan $0-16$ untuk masingmasing butir tes. Skor ideal yang diberikan bervariasi, karena keluasan materi konsep yang ingin dicapai setiap soal berbeda (Asmawi \& Noehi, 2001: 49).

Setelah memperoleh data melalui tes, juga diadakan observasi yaitu dengan mengadakan pengamatan terhadap proses belajar bahasa Indonesia dengan topik letsikalistik, dengan memfokuskan pada keaktifan siswa dalam proses belajar mengajar.

Dalam penelitian ini tahap pengumpulan data secara garis besar dilakukan dengan beberapa tahapan sebagai berikut : Tahap pertama : adalah pada saat observasi pendahuluan dilakukan hingga identifikasi awal permasalahan dengan model pembelajaran yang diterapkan. Tahap kedua : pelaksanaan analisis dan refleksi terhadap setiap tindakan (siklus 1 3). Tahap ketiga : menganalisis dan membahas perubahan konsepsi siswa dengan membandingkan hasil tes awal dan tes akhir. Tahap keempat : data dalam penelitian itu guru dan siswa tentang pembelajaran dengan menggunakan model nyanyian sebagai instrumen test.

Analisis data dalam penelitian itu dilakukan melalui tahapan-tahapan katagori data, validasi data, dan interpretasi data. Kegiatan 
refleksi awal ini merupakan deskripsi situasi dan bahannya berdasarkan catatan guru yang terlibat dalam penelitian ini. Dari deskripsi masalah yang muncul merupakan operimalisasi pembelajaran menulis dan mengapresiasikan bacaan yang sesuai dengan konsep dalam GBPP, mata Pelajaran Bahasa Indonesia (berdasarkan catatan guru meningkatkan kemampuan apresiasi membaca dengan menggunakan nyanyian),

Kegiatan dan bahan yang dipersiapkan guru dalam melaksanakan tindakan ini adalah : (a) Menganalisis komponen, aspek dan isi butir pembelajaran (Analisis Butir Pembelajaran ), (b) Penetapan materi Pembelajaran (RPP,LKS) dan (c) Pengembangan model penilaian atau assegment, (d) Penyusunan instrumen penjaringan data secara garis besar perencanaan tindakan ini dilaksanakan.

Siswa ditugasi secara kelompok memilih dan mendengarkan lagu anak-anak yang banyak beredar di masyarakat (sebagai tugas rumah). Sebelumnya guru sudah mempunyai kelompok tersebut ditugasi : (1) Menulis bacaan yang didengarkannya, (2) Mengertikan kata-kata sulit, (3) Memafrase kalimat, (4) Memberikan komentar tentang makna dalam stun paragraf. Dilaksanakan untuk mengukur proses pembelajaran, khususnya minat dan antusiasme siswa terhadap model pembelajaran membaca dengan menggunakan nyanyian sebagai alat apresiasi. Peneliti (dibantu kolaborator ) menggunakan instrumen penilaian yang berupa : Pemaknaan kata sulit dalam bacaan yang dapresiasikan, minat dan antusiasme siswa.

Penialaian hasil dilaksanakan untuk mengukur keberhasialan belajar siswa atau pencapaian tujuan pembelajaran, khususnya peningkatan apresiasi bacaan siswa (Pemaknaan kata sulit/kata kias/majas, pemfrase, komentar segi bahasa). Peneliti (dibantu kolaborator) menggunakan instrumen penilaian berupa butir soal yang mengukur kemampuan apresiasi siswa lewat lagu mulai dari pemaknaan kata sulit.

Pelaksanaan tindakan slklus I terdiri dari dua pertemuan, masing-masing pertemuan dua jam pelajaran, Pertemuan pertama (2 jam pelajaran ) adalah untuk mencapai tujuan pembelajaran pertama kedua ( 2 jam pelajaran ) untuk mencapai tujuan pembelajaran kedua. Silkus II dilaksanakan berdasarkan hasil refleksi siklus I jumlah pertemuan dan jam tetap muka disesuaikan berdasarkan pertemuan siklus I.

Kolaborator yang dilibatkan dalam pelksanan tindakan ini adalah guru Bahasa Indonesia, serta siswa tempat guru melaksanakan penelitian tindakan kelas ini. Guru sebagai kolaborator akan mengamati pelaksanan KMB dengan meggunakan pedoman observasi yang telah disiapkan. Kolaborator dari siswa dari respon dan jawaban siswa ketika KMB berlangsung. Data dapat dijaring melalui wawasan siswa dan guru serta jawaban siswa dari kuesioner yang disebarkan di kelas setelah KMB berlangsung.

Seluruh data yang dijaring diharapkan dapat dianalisa secara kuantitatif agar dapat menentukan keberhasilan penelitian tindakan kelas ini.

Silkus II dilaksanakan sebagai kelanjutan siklus II, terutama jika terjadi kekurang tepatan dalam perencanaan siklus I. Kekurang tepatan itu misalnya : situasi kelas berubah, perkembangan baru, kondisi siswa, dan / atau materi pelajaran. Siklus kedua tidak dilaksanakan jika hasil penelitian tindakan kelas sudah sesuai dengan target ketuntasan belajar (65\% perorangan dan $85 \%$ klasikal). Sebaliknya bila target ketuntasan belajar belum tercapai, siklus kedua akan dilaksanakan.

\section{HASIL TINDAKAN DAN INTERPRETASI}

Masalah dalam pembelajaran membaca adalah kegiatan pembelajaran belajar menoton dan menjemukan, serta bahan pembelajarn kurang menarik. Selin itu kegiatan pembelajaran menulis dan membaca juga tidak disajikan dalam keterpaduan empat aspek ketrampilan berbahasa, sehingga kegiatan pembelajaran terasa kaku dan sepotong-sepotong. Aspek emosi siswa terasa kering karena kekurang mampuan guru menciptakan suasana pembelajaran yang menyenangkan.

Membaca bagi siswa di SDN 04 Koto Ranah Kecamatan IV Nagari Bayang Utara Kabupaten Pesisir Selatan sulit apalagi dalam menginterpretasikan arti dari isi bacaan terutama bagi siswa kelas I SDN 04 KOTO RANAH Kecamatan IV Nagari Bayang Utara Kabupaten Pesisir Selatan Tahun Pelajaran 2015/2016 banyak menemukan kesulitan, apalagi jika 
bacaan yang harus mereka ekspresikan kurang menarik dan kurang sesuai dengan tingkat perkembangan siswa.

Kegiatan pembelajaran dengan gaya menyanyi dapat disajikan dengan menggunakan strategi atau pendekatan pembelajaran yang diharapkan dapat mengatasai permasalahan pembelajaran membaca, Kegiatan pembelajaraan dapat berjalan wajar sesuai dengan realita kehidupan dan menyenangkan. Sebelum kegiatan pembelajaran, siswa dapat ditugasi untuk mendengarkan lagu dirumah secara kelompok., Tugas setiap kelompok tersebut adalah : (a) Mencatat bacaan yang didengarkan, (b) Memaknai kata sulit tiap baris dalam bacaan tersebut, (c) Mengomentari isi bacaan tersebut. Tujuan pembelajaran pada pertemuan II ini adalah : Membaca bacaan dengan menyanyikan bacaan. Sesuai langkahlangkah dalam RPP Pertemuan I.

Pertemuan II, Tujuan pembelajaran pada pertemuan II ini adalah : Menuliskan pengalaman pribadi yang paling menarik dalam bentuk bacaan. Sesuai dengan langkah-langkah dalam RPP Pertemuan II.

Lembar Observasi digunakan pada pertemuan I dan II. Lembar Observasi ini meliputi “ (a) Identivikasi perencanaan pembelajaran, (b) Pengamatan pelaksanaan pembelajaran, (c) Identifikasi pelaksanaan pembelajaran.

Semua tahapan / butir dalam pelaksanaan pembelajaran telah dilaksanakan dengan positif $(100 \%)$, demikian juga kegiatan siswa. Antusiasme siswa terhadap kegiatan pembelajaran terlebih jelas dari perasaan mereka yang terpancar pada kegembiraan mereka membahas dan mengkomentari puisi yang diperdendangkan guru, juga dari komentar mereka tentang model kegiatan pembelajaran menyanyi dengan menggunakan lagu. Mereka merasa lebih mudah memahami isi bacaan dari pada diberi bacaan secara langsung.

Wawancara dilaksanakan oleh kolaborator aktif kepada kolaborator pasif setelah kegiatan pembelajaran berlangsung, Dari 10 butir pertanyaan dalam pedoman wawancara untuk guru tersebut dapat disimpulkan bahwa seluruh butir pertanyaan terjawab positif $(100 \%)$

Dari 10 butir pertanyaan dalam dalam pedoman wawancara untuk siswa secara keseluruhan terjawab positif $(100 \%)$ Dari hasil wawancara tersebut dapat disimpulkan bahwa pelaksanaan kegiatan pembelajaran membaca dengan menggunakan pola nyanyian sangat disukai oleh siswa.

Hasil koesioner untuk siswa menyebutkan bahwa empat aspek ketrampilan berbahasa (menyimak, berbicara, membaca dan menulis ) dilaksanakan dengan porsi yang seimbang. Selain itu siswa merasa lebih mudah memahami dan mengekspresikan nyanyian sebab menurut mereka lagu juga menggunakan bahasa puitis

Pada pertemuan ini siswa mendengarkan bacaan yang dibaca oleh guru. Kemudian mengerjakan tugas-tugas yang ada pada LKS I. Tugas pertama adalah melengkapi kalimat rumpang dalam syair lagu kata-kata yang tepat / sesuai dengan lagu yang dirumpangkan tersebut. Dari 24 siswa, siswa yang lain salah I sampai 5 ada 20 siswa atau $89,36 \%$ yang 4 siswa $(10.64 \%)$ salah 6 sampai 8 sehingga dapat disimpulkan bahwa kegiatan mendengarkan ini $89 \%$ berhasil / tutas

Tugas berikutnya adalah mendiskusikaan makna tiap bait dalam bacaan. Pada kegiatan ini siswa mengalami kesulitan sebab bacaan yang diperdengarkan tersebut tidak terlalu sulit. Kegiatan ini dilanjutkan dengan memfrasekan kalimat dengan cara menyadurkan menjadi sebuah paragraf. Kegiatan ini pun dapat berjalan dengan lancar, meski ada beberapa siswa yang memfrasekan dengan cara merangkai kalimatkalimat dalam lagu. Setelah menjelaskan cara memfrasekan dengan memberi contoh-contoh yang dikaitkan dengan kehidupan sehari-hari, akhirnya siswa dapat mengekspresikan lagu tersebut dengan tepat.

Pada saat siswa diminta untuk memberikan komentar tentang isi dan bahasa lagu tersebut. Rata-rata siswa menyatakan bahwa bahasa lagu tersebut cukup puitis. Komentar siswa terhadap isi lagu rata-rata menyatakan bahwa isi syair lagu tersebut sangat menarik dan berhubungan dengan lingkungan alam.

Selanjutnya pada waktu siswa membacakan lagu tersebut dengan vokal, lafal, intonasi dan penjiwaan / ekspresi yang tepat. Hal ini terbukti pada saat beberapa siswa (yang ditunjuk secara acak ) ditugasi membacakan lagu tersebut ke depan kelas. Sedangkan mengomentari pembaacaan teman lain, membetulkan kesalahan yang terjadi dengan memberikan contoh membacakan bait lagu tersebut.

Hasil kegiatan belajar siswa pada pertemuan II ini adalah tercipnya sebuah bacaan 
tentang alam. Untuk memudahkan penciptaan kata tentang lingkungan alam tersebut guru mengawali kegiatan pembelajaran melalui memperdengarkan lagu yang berkaitan dengan alam. Selain itu, guru juga membawa alat peraga yang berupa beberapa gambar tentang lingkungan alam. Dari mendengarkan dan memperlihatkan gambar tentang lingkungan alam tersebut siswa ditugasi menyusun sebuah kalimat bacaan tentang lingkungan alam berdasarkan imajinasi mereka.

Puisi yang dihasilkan oleh siswa dikumpulkan, kemudian dipilih secara acak untuk dibacakan tersebut. Kalimat yang diciptakan siswa yang dikumpulkan tersebut nilai isi dan bahasanya.

Dari kegiatan pertemuan II ini diperoleh kesimpulan bahwa isi puisi rata-rata sudah baik dan sesuai dengan tema (lingkungan alam). Bahasa dalam kalimat juga sudah puitis, dalam arti tidak hanya menggunakan kata-kata seharihari. Rata-rata sekor yang diperoleh siswa adalah 88. Jadi, kegiatan pembelajaran pada pertemuan II ini dinyatakan $88 \%$ tuntas.

Penggunaan lagu yang disajikan sebagai alat dan bahan untuk apresiasi bacaan dalam kegiatan pembelajaran ini telah berhasil pada siklus I, Berdasarkan refleksi pada siklus I, aktivitas belajar siswa cukup optimal. Siswa merasa mudah membacakan lagu bahasanya memang cukup puitis. Dapat dikatakan kegiatan pembelajaran pada siklus I pertemuan I berhasil dengan cukup baik.

Demikian juga pada kegiatan alam, imajinasi siswa lebih tergugah setelah mendengarkan lagu tentang alam yang diperdengarkan oleh guru. Sehingga kegiatan pembelajaran pada pertemuan kedua ini pun berhasil dengan memuaskan. Hal ini tampak pada hasil karya siswa tentang lingkungan alam yang selanjutnaya dijilid memjadi sebuah kumpulan karangan dan simpan sebagai salah satu koleksi perpustakaan.

Tindakan pada siklus II tidak dilaksanakan karena siklus I sudah cukup berhasil. Hasil kegiatan pembelajaran yang tampak pada siklus I sudah menunjukkan ketuntasan belajar yang cukup memuaskan.

Kegiatan pembelajaran membaca dengan menggunakan lagu sebagai alat apresiasi dapat berjalan dengan optimal. Empat aspek ketrampilan berbahasa (menyimak, berbicara, membaca dan menulis ) dapat dilaksanakan secara terpadu dalam keguatan pembelajaran. Tujuan pembelajaran pada pertemuan I dan II dapat tercapai dengan baik. Hal ini terlihat pada saat siswa mengapresiasikan lagu dan membacakannya $88 \%$ dinyatakan tuntas dalam menulis sebuah karangan tentang lingkungan alam.

Berdasarkan uraian tersebut, hipotesis yang diajukan dalam penelitian ini : "kemampuan siswa meningkat dalam apresiasi membaca tehadap mata pelajaran bahasa indonesia, dengan menggunakan metode nyanyian di SDN 04 KOTO RANAH Kecamatan IV Nagari Bayang Utara Kabupaten Pesisir Selatan Tahun Pelajaran 2015/2016 " dapat diterima

\section{KESIMPULAN DAN SARAN}

Berdasarkan apa yang telah penulis laksanakan, dapat ditarik beberapa kesimpulan yaitu bahwa : Latihan membaca dalam proses belajar mengajar dengan teknik menyanyi lebih mudah ditangkapa oleh siswa kelas I SDN 04 Koto Ranah Kecamatan IV Nagari Bayang Utara Kabupaten Pesisir Selatan Tahun Pelajaran 2015/2016 . Selama kegiatan ini berlangsung, terlihat adanya kesungguhan dari anak-anak untuk mengikuti pelajaran. Anak-anak bisa belajar membaca tanpa merasa tertekan dan selalu dalam suasana yang menyenangkan. Hasil monitoring secara kuantitatif menunjukkan bahwa $75 \%$ anak-anak mampu membaca lancar sehingga mengajak siswa kelas I SDN 04 Koto

Ranah Kecamatan IV Nagari Bayang Utara Kabupaten Pesisir Selatan Tahun Pelajaran 2015/2016 latihan membaca dengan teknik menyanyi terbukti mampu menumbuhkan minat baca anak sejak dini.

Program pertemuan guru dengan orang tua murid yang dilaksanakan sebulan sekali sebelum menyampaikan materi kepada anakanak sangat besar pengaruhnya dalam membantu keberhasilan anak-anak belajar di SDN 04 Koto Ranah Kecamatan IV Nagari Bayang Utara Kabupaten Pesisir Selatan Tahun Pelajaran 2015/2016 . Penulis menyadari bahwa penyampaian materi tersebut belum dilaksanakan secara maksimal, mengingat jumlah anak yang 
melebihi kapasitas. Apabila dilaksanakan lebih intensif dan dengan rasio perbandingan guru dan anak yang ideal, maka secara kuantitatif maupun kualitatif tentu hasilnya akan lebih baik.

Mengacu pada kesimpulan diatas, diharapkan apa yang penulis sampaikan mampu memberi masukan yang positif, khususnya bagi guru SDN 04 Koto Ranah Kecamatan IV Nagari Bayang Utara Kabupaten Pesisir Selatan
Penulis menyarankan agar teknik menyanyi sebagai upaya menumbuhkanminat baca anakanak SD diterapkan dalam proses belajar mengajar. Semoga, tulisan ini mampu menggugah para orang tua yang memiliki anak usia SD agar dalam mengajarkan membaca dilaksanakan secara bijaksana dan dengan teknik yang sesuai dengan usia anak. 


\section{DAFTAR PUSTAKA}

Doman, Glenn,1985, Ajaklah Balita Anda Belajar Membaca. Yayasan Essentia Medica, Yogyakarta.

Rochmat Wahab, 1996. Pendidikan Anak Berkat di Usia $S D$. Artikel dalam Sehari yang Diselenggarakan oleh PGSD I Bina Insan Mulia, Yogyakarta

Yulia Ayriza dkk, 2000,Menumbuhkan Kesiapan Membaca Anak SD melalui Latihan Kesadaran Fonologis dengan Lagu Kanak-kanak Bersilabel dan Berfonem. Laporan penelitian, Fakultas Ilmu Pendidikan Universitas Negeri Yogyakarta, Yogyakarta.
Agung Sudalbo, 2004. Belajar Membaca Sambil Bernyanyi. Bina Insani, Yogyakarta.

Dave Meier. 2002. The Eccelerated Learning.Bandung : Kaifa.

Departemen Pendidikan dan Kebudayaan. 2002. Petunjuk Pelaksanaan Penilaian di Sekolah Dasar. Jakarta

Departemen Pendidikan dan Kebudayaan. 2003. GBPP Sekolah Dasar Kelas V. Jakarta

Departemen Pendidikan Nasional. 2002. Kebijakan Direktorat pendidikan TK dan SD tahun 2002. Jakarta

Gordon Dryden dan Jeannette Vos.2001. Syair Dalam Pembelajaran Bahasa Indonesia. Bandung : Kaifa 